\title{
National Bureau of Standards One Kilogram Balance NBS No. 2
}

\author{
H. E. Almer \\ Institute for Basic Standards, National Bureau of Standards, Washington, D.C. 20234
}

(January 17, 1972)

\begin{abstract}
The balance described is a one-pan, two-knife, short arm, $1 \mathrm{~kg}$ balance. The fulcrum flat and the suspension support elements are mounted on a bed plate supported by three posts attached to the base. The weight handling mechanism is mounted on a center column attached to the base. The balance has two modes of arrestment, the constant load mode and the full arrest mode. A double case encloses the structure.

There are positions for six weights inside the balance. These weights can be compared with each other, according to an appropriate weighing design, without opening the balance case. The operation of the balance and the weight changing are through control elements outside the balance case. The indicating elements for the instruments measuring the pressure, temperature, and relative humidity within the balance are located inside the balance.

The standard deviation of the balance developed by a series of measurements in the National Bureau of Standards Experimental Mass Laboratory was approximately $4 \mu \mathrm{g}$.
\end{abstract}

Key words: Arrestment; balance; beam; buoyant; case; constant-load; equilibrium; knife; one-pan; short arm; two-knife.

\section{Introduction}

In a continuing program to improve mass measurements, the Mass Section of the National Bureau of Standards designed and constructed a high precision one kilogram capacity balance. After a detailed consideration of the two-knife single pan balance and the three-knife equal arm two-pan balance, a short arm (2 in) two-knife one-pan balance design was chosen principally because $[1,2]:{ }^{1}$

(1) The geometry associated with the two knife design simplifies adjustments.

(2) This design lends itself to the use of a constant load type of arrestment; that is, the knives are not separated from their cooperating planes during the weighing operation, nor is the mechanical load carried by the knife-plane combination significantly changed between the loaded and unloaded condition.

(3) Versatility of weight handling and weight changing is achieved.

(4) A stiff beam is practical.

Several features were incorporated in the balance design.

(1) The arrestment was designed so that during a series of weighings the knives are always under load, and the knives and their cooperating planes are not separated when weights are interchanged.

${ }^{1}$ Figures in brackets indicate the literature reference at the end of this paper.
(2) The load is applied and removed smoothly by mechanical means.

(3) All operations are controlled from outside the balance case, so that it is not necessary to open the balance during a weighing.

(4) The beam with its short arm is as rigid as practicable, nearly homogeneous, and has good thermal qualities. Cylindrical wedges are used to adjust and retain the knives. This adjusting method was used with permission of Voland Corporation. ${ }^{2}$

(5) The suspension includes a ball bearing gimbal between the cross-knife and the pan.

(6) The upper part of the suspension includes a Thiesen compensator consisting of a knife whose edge was nominally in the same plane as the load knife of the beam.

A test instrument embodying these concepts was built and tested. ${ }^{3}$ Results of mass measurements with this test instrument were encouraging and had standard deviations varying from $3 \mu \mathrm{g}$ to $8 \mu \mathrm{g}$ [3]. These results led to the conclusion that a practical balance embodying these principles and concepts with at least as good if not better precision was possible.

The present balance, designated NBS No 2, may be described as a one-pan, two-knife beam, constant load

\footnotetext{
${ }^{2}$ The Voland Corporation holds a patent on the use of cylindrical wedges for adjusting knives in a balance.

${ }^{3}$ This prototype was designated NBS No. 1 for working purposes only. Prototypes NBS Nos. 3,4 , and 5 are being built.
} 
balance. It embodies the above features and others deemed desirable from experience gained with the test instrument and during the development of the present balance. These include:

(1) The beam, suspension system and load are in buoyant and mass equilibrium $[2,4]$.

(2) A beam brake is provided to prevent excessive movement of the oscillating system during release and arrest. The brake may also be used to limit the amplitude of the oscillation.

(3) A heat source above the balance is provided to maintain a positive vertical gradient (warmer at top) [5].

(4) The case was designed to minimize the horizontal gradient, optimize the vertical gradient within, and insulate the balance from the room environment.

\section{Description}

The base of the balance sits on a base plate. Mounted in the base is a center column supporting the weight changing and storage members. The fulcrum bearing stand and various other components are mounted on a bed plate supported on three posts attached to the base; the plate is otherwise independent of the weight changing mechanism.

The short-arm two-knife beam and the suspension were designed so that the oscillating system is in buoyant equilibrium when the load is on the pan [4]. Two modes of arrestment are provided [3]. In one, denoted the full-arrestment mode, the knives and the bearing planes are separated. This mode of arrestment is used when the balance is not in use. In the other mode, denoted the constant-load arrestment mode, the knives with bearing planes are not separated. This mode of arrestment is used during weighing operations.

The balance mechanism is enclosed in a double case with windows for the optical lever of the readout and for viewing the position of the weight carrier. The reading scale is reflected through a series of mirrors from the mirror mounted on the beam to the telescope.

The controls are brought out through the base. Instrumentation for reading the pressure, temperature and relative humidity within the balance case is provided.

\subsection{Base and Supporting Structure}

The base of the balance is a shallow cup-like component made from heavy aluminum, which sits on a base plate supported by three leveling screws.

The center column, which is attached to the base by brackets through a column base plate (see fig. 1), supports the weight changing mechanism and the weight carrier. Three posts support the bed plate upon which are mounted the fulcrum bearing stand, the arrestment-alinement pins, the full-arrest beam lifter, the tit-stop for the constant-load arrestment, the fixed elements of the optical read-out, the beam brake bracket, and the sensitivity weight support. The bed plate is a 1 inch brass plate $11 \frac{1}{2}$ inches in

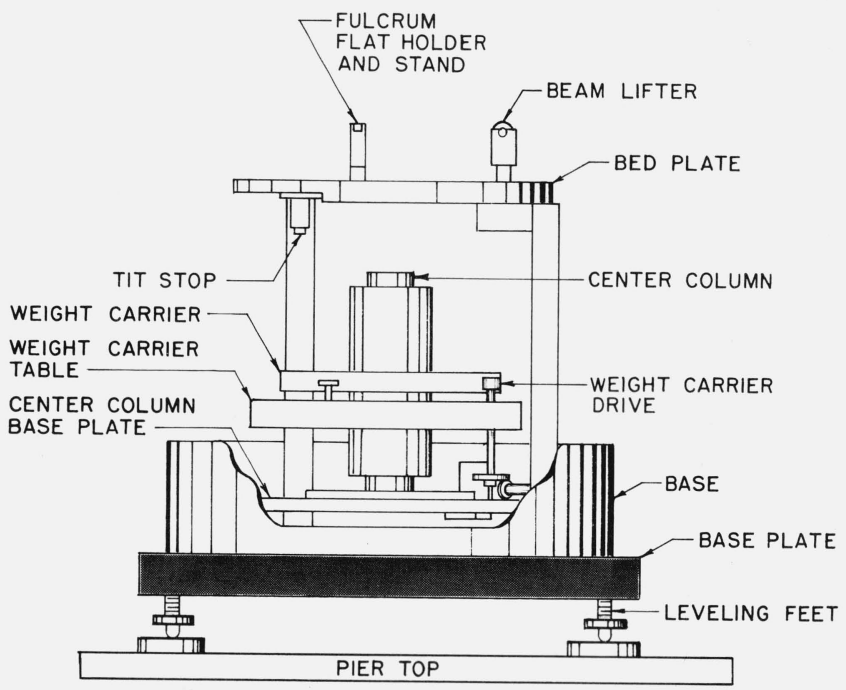

FIGURE 1. Schematic sketch of balance structure.

diameter. All the components except the beam lifter and the tit stop are mounted on the top of the bed plate. The beam lifter extends above the bed plate, but its drive gears are below the bed plate and are enclosed in a gear box. The beam lifter moves vertically to arrest or release the beam. The roller which engages the beam has a ball bushing so it can move laterally on its shaft, which has ball bearings for rotational motion. The tit-stop mounted on the underside of the bed plate is adjustable as to height. The fulcrum bearing flat is a piece of boron carbide $2 \frac{1}{2}$-in long with a $\frac{3}{8}$-in square cross section.

\subsection{Weight Changing Mechanism}

The weight changing mechanism's vertical travel, of $\frac{3}{8}$ in, on the center column is guided by an upper and a lower bearing spaced $5 \frac{3}{4}$ in apart, and actuated by a cam. A horizontal plate forming a table has three sets of ball bearings supporting the weight carrier, which has positions for six weights. The weight carrier is positioned on the weight table by two ball bearing guide rollers and one drive roller (see fig. 2). The drive roller rotates the weight carrier by a friction drive and is itself driven by a friction gear attached to the control rod. This friction gear is designed so that when the weight table is lowered to the weighing position it is disengaged.

\subsection{The Beam}

The beam of the balance is T-shaped, two knife type, consisting of a beam body to which are attached two bosses, a mirror, two out riggers, and the two knives. A pair of counter-weights are attached to the bosses. The equilibrium and sensitivity adjusting pieces complete the beam. Figure 3 shows an exploded view of the beam.

The beam body is gold-plated brass. The knife seats are spaced so that the nominal arm length is $2 \mathrm{in}$. The 


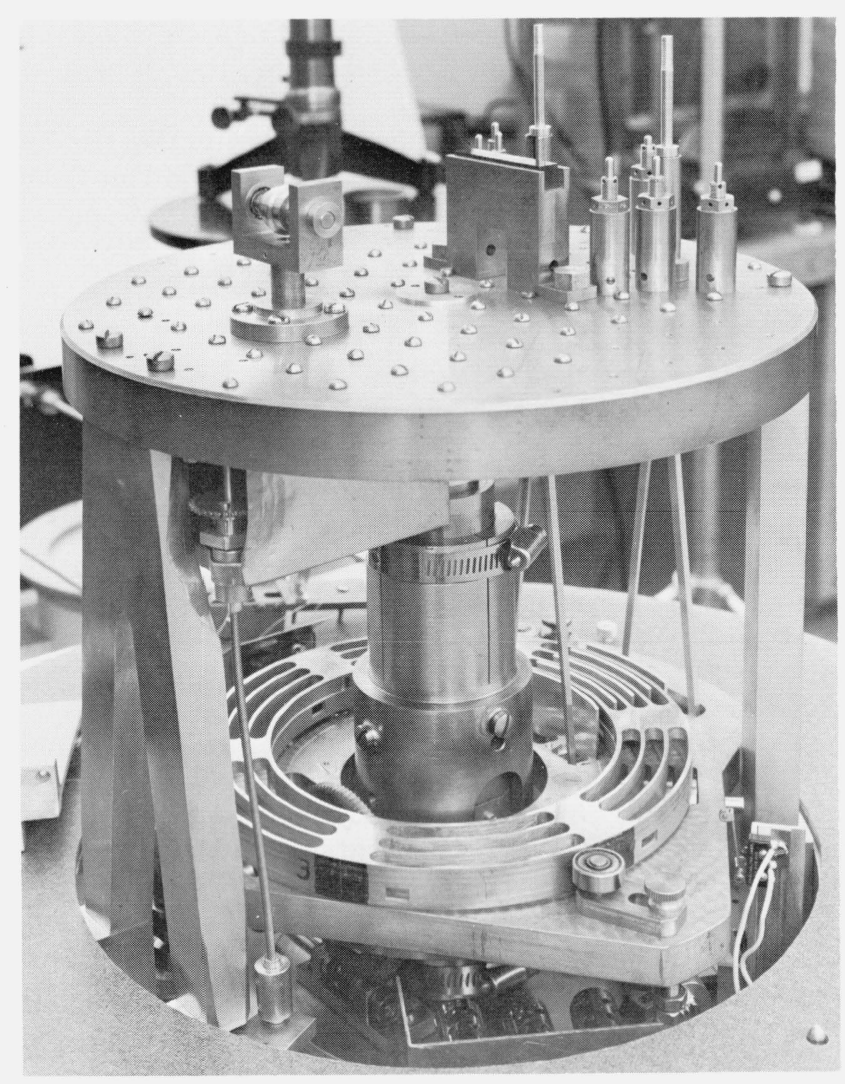

FIGURE 2. Photograph of balance structure showing weight table, weight carrier and pan.

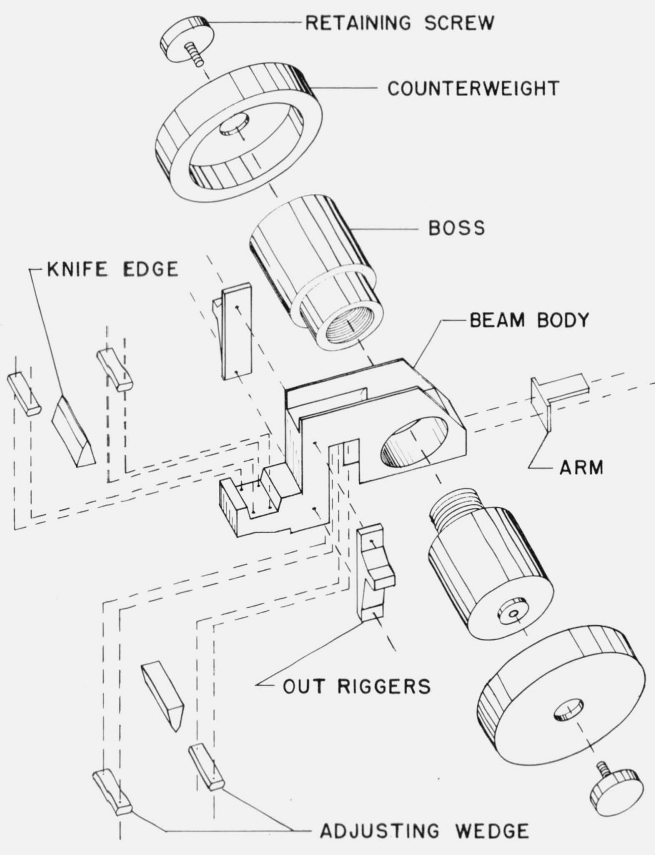

Figure 3. An exploded sketch of the beam. knive seats were scraped to provide a flat seat for the knives, which are attached to the beam with cylindrical wedges. These cylindrical wedges serve both as a means of adjusting the knives and as a means of retaining the knives in position. The knife material is Tantung $\mathrm{G}$ and the included angle between the knifeedge facets is $120^{\circ}$. At the back of the beam 2 in from the design position of the fulcrum knife is a transverse hole $1 \frac{1}{4}$ inch in diameter to receive the two bosses, to which the two counter-weights are attached by means of gold plated brass retaining screws. The face of the retaining screws that meets the counter-weight is conical and holds the counter-weight securely in position. The bosses are two aluminum cylinders, one with a threaded male portion and the other with a mating threaded female portion. The bosses together with the retaining screws are designed to have the same mass and volume as the suspension system.

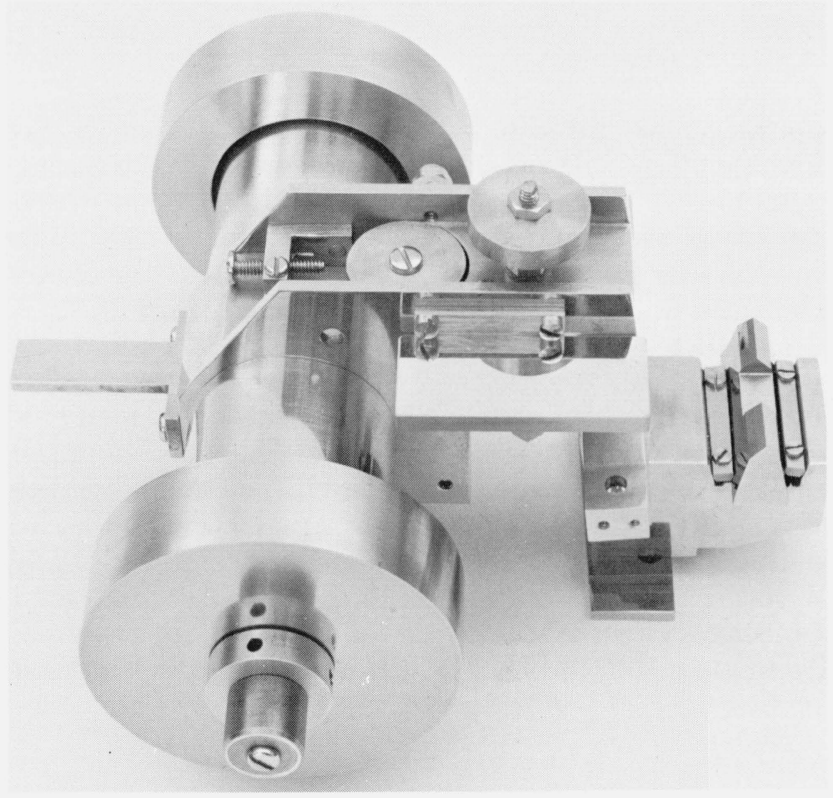

FigURE 4. View of the beam from the mirror side.

The balance was designed so that the counterweights and the load on the pan be of materials having the same or nearly the same densities. Therefore, the counter-weights are interchangeable. When stainless steel weights are compared stainless steel counterweights are used and when platinum-iridium weights are compared platinum-iridium counter-weights are used. This minimizes the drift of the balance with changing conditions, because the oscillating system of the balance is near buoyant equilibrium. In figure 4 , the beam is shown with stainless steel counter-weights.

\subsection{The Suspension System}

The suspension system (fig. 5) consists of the pan including risers which attach the pan to the ball bearing gimbal, a part of the suspension, the yoke in which is 


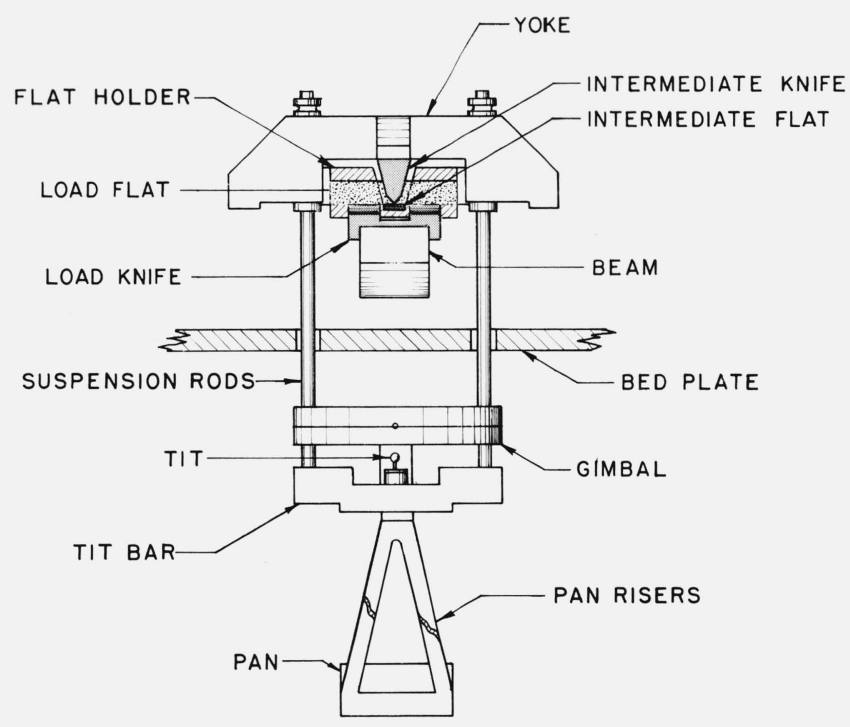

FIGURE 5. Schematic sketch of the suspension system.

mounted the intermediate or cross-knife, an intermediate flat holder, and the necessary connecting elements. Also included is the tit and tit-bar on which the tit is mounted. The tit is attached to the yoke through the rods connecting the gimbal to the yoke. The tit is below the gimbal.

Except for the cross-knife, the flats, the ball bearings in the gimbal, the tit, and various screws and other fasteners, the suspension components are made of aluminum. The intermediate knife, which is mounted in the yoke, is made of Tantung. The load bearing flat and the intermediate bearing flat are mounted in the intermediate flat holder. The load flat is made of boron carbide while the intermediate flat is made of Tantung. The ball bearings in the ring type gimbal are made of beryllium. The pan was designed to permit the circular weight carrier to place the weight on the pan or remove it from the pan (see fig. 2) with a minimum disturbance.

The vertical ribs of the pan mesh with the ribs of the weight carrier. Means for separating the pan from the rest of the suspension, without other disassembly, are provided.

\subsection{The Indicating System}

The indicating system (fig. 6) consists of an illuminated scale located about three meters from the balance; a moving mirror mounted on the beam; three fixed mirrors, two mounted on the bed-plate and one attached to pier outside the balance case; and a reading telescope.

The first of the fixed mirrors mounted on the bed plate directs the image of the reading scale to the moving mirror, attached to the beam, from which it is reflected to the second fixed mirror, which is mounted above the beam mirror at an angle of about $30^{\circ}$. The path of the image between the second fixed mirror and the beam mirror has three reflections from the beam mirror. The last reflection directs the image to the first fixed mirror which then reflects the image to the fixed mirror outside the balance. The image is then reflected to the reading telescope, which has a reticle with a horizontal hair line, where the balance indication is read.

\subsection{The Case}

The balance has a double case. Both the inner and outer cases are in the form of right circular cylinders. The inner case consists of the three parts; an upper part, which encloses the beam compartment; a lower part which encloses the weight and pan compartment, and can be raised up over the upper part; and the cover. The lower part is fitted with handles for lifting

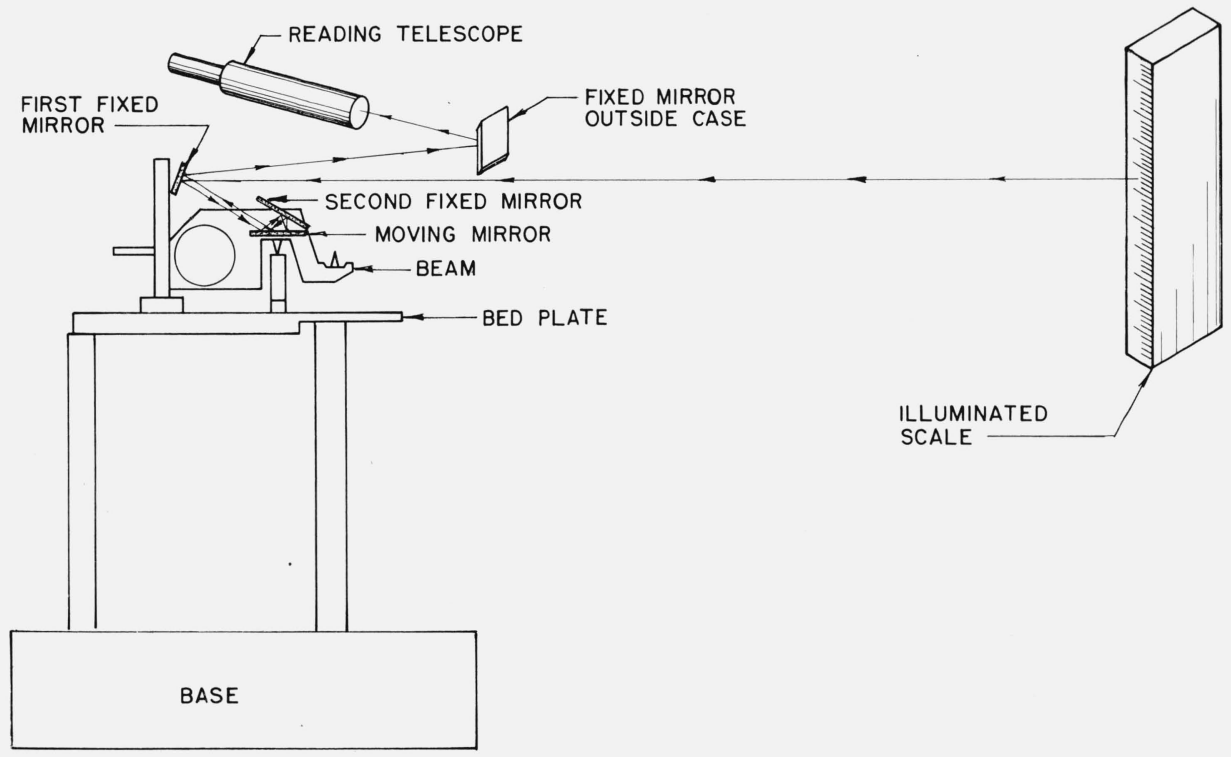

FigURE 6. Schematic sketch of the balance indicating system. 
and latches to hold it up when weights are being positioned on the weight carrier. The cover is an aluminum disk $\frac{5}{8}$-in thick equipped with lifting handles. Both the upper and lower parts are built-up of alternating rings of insulating material and aluminum. The insulating rings are 1 -in high and $\frac{3}{4}$-in thick. The aluminum rings were cut from D'ds-in stock and are l-in wide. The inside of the inner case was lined with 0.005-in stainless steel sheets fitted between the aluminum rings. The outside is covered with pressed fiber board.

The outer case is also a built-up case of alternating rings of hard board and insulating material, with an outside skin of sheet aluminum. The hardboard rings were cut from $\frac{1}{4}$-in stock. The insulating rings are 5 -in high and $\frac{3}{4}$-in thick (fig. 7). The cover is also of hardboard.

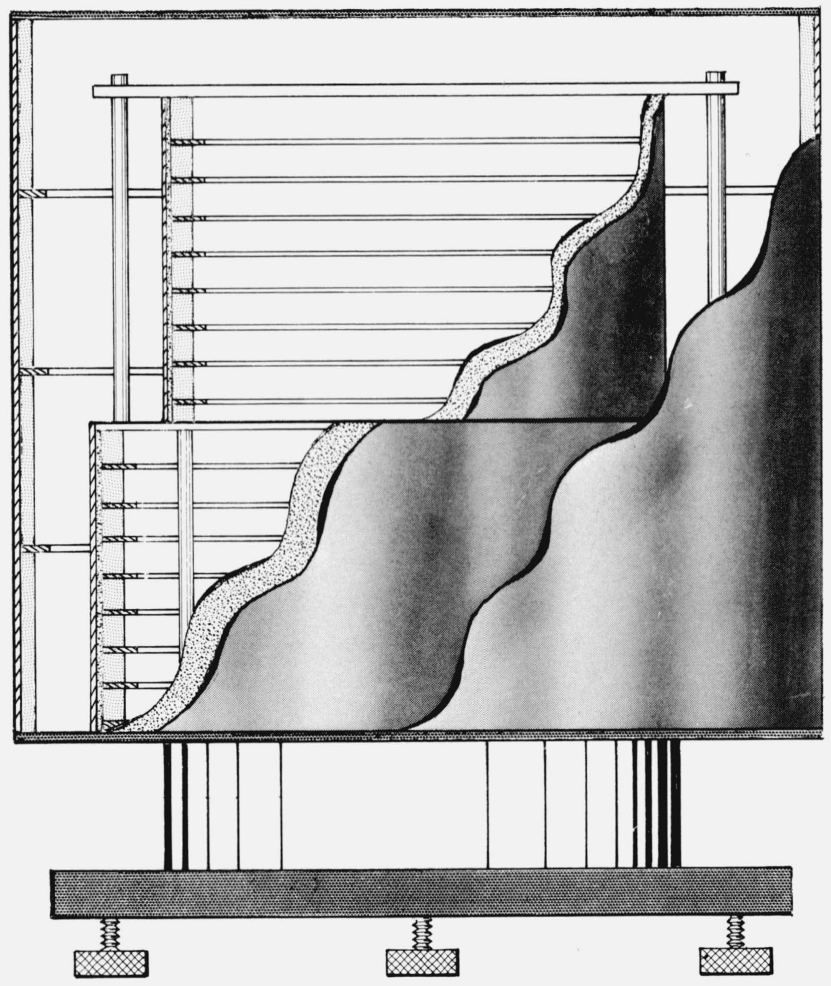

FigURE 7. Cut-away view of the balance case.

In both the inner and the outer case, the insulating rings were made from corrugated paper rolled to form rings, $\frac{3}{4}$-in thick.

The aluminum rings in the inner case form fins to maintain a nearly isothermal horizontal gradient inside the balance.

\subsection{The Controls}

There are six controls and all but the full arrest control extend to a control panel at the side of the balance convenient to the operator at the reading telescope. The control rod for raising and lowering the weight table is driven by a variable speed electric motor. The motor control box is connected to the motor by a cable so that it can be located in a convenient position. The sensitivity weight, the beam brake, the weight changing, and the full arrest controls are all manually operated. Even though a pan brake was not installed, a control for one was included if it is desired in the future (see fig. 8).

Provision was made for measuring the pressure, relative humidity and temperature within the balance case.

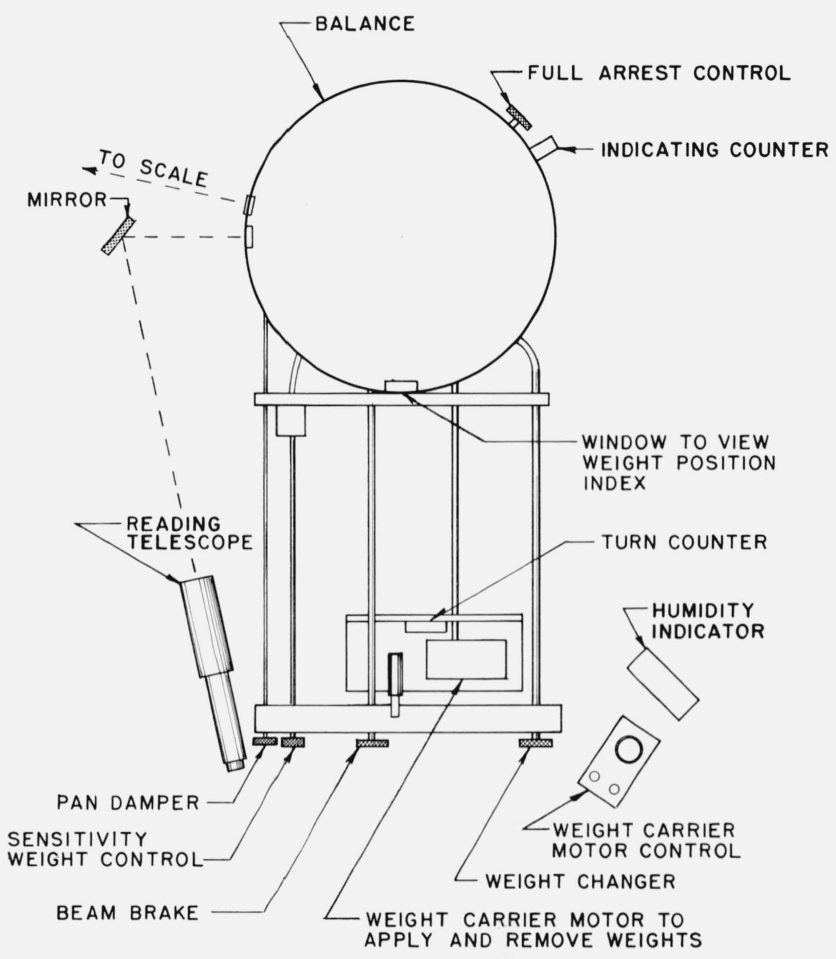

FIGURE 8. Schematic sketch of the balance controls.

\subsection{The Arresting System}

The balance has two arrestment modes or arresting systems. In one, designated the full arrest mode, the knife edges and their cooperating flats are separated when the balance is arrested. The other mode, designated the "constant load" mode, the knives are not separated from their cooperating flats. The contact forces between the knives and flats, when arrested in the "constant load" mode and during the arresting operation varies only slightly from their operating levels. The parts of the arresting systems responsible for the alinement of the beam and the suspension do not move, further minimizing arrestment errors. [3]

The essential features of the full arrest mode are shown in figure 9. In the top view, the balance is shown in the weighing position. In the second view, the beam lifter raised the counterweight end of the beam and lowered the load end until the load flat and the rest of suspension is supported by the alinement-arrestment pins. This is termed the partial arrest. 

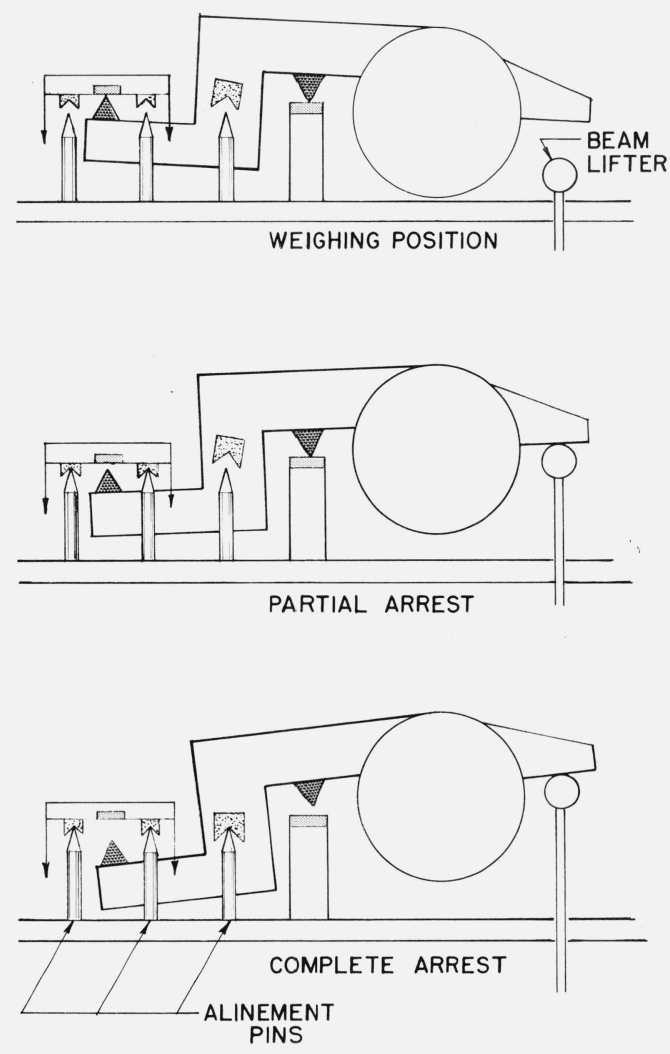

FIGURE 9. The full arrest mode of arrestment.

In the bottom view, the beam lifter has raised the counterweight end of the beam until the beam is supported by its alinement-arrestment pins and the beam lifter and the fulcrum knife is separated from its flat.
The beam lifter does not contribute to the alinement in the arresting operation because it was fabricated from a roller with a ball bushing riding on shaft with ball bearings. Thus, any horizontal component is taken up by the ball members.

The essential features of the constant load mode of arrestment are shown in figure 10. In the first view (left), the balance is shown in the weighing or released position. In the second view (middle), the weight carrier has been raised so that it is in contact with the weight on the pan. As the weight carrier gradually moves upward lifting the weight, the suspension follows the weight until the tit comes into contact with the tit stop, preventing further upward movement of the suspension. The weight carrier continues to move upward until the weight is free and clear of the pan. When the pan is empty, the force between the tit and the tit stop is about $1 \mathrm{~kg}$. The balance is now arrested in the constant load mode. This condition is shown in the third view (right). The next weight may now be brought to the pan and lowered onto it.

\section{Adjustment}

Basic to the proper adjustment of the balance is that the balance be level. Specifically this means that the fulcrum flat is level (fig. 11). With the fulcrum flat level the height of the alinement-arrestment pins was adjusted so that when the load and the fulcrum knives lie in the same horizontal plane, the beam is at the midpoint of its travel. The weight carrier table is adjusted so that the weight carrier surface on which the weights rest is level. With the balance mechanism assembled the alinement-arrestment pins are further adjusted so that the knife edges meet their cooperating flats simultaneously along their entire length.
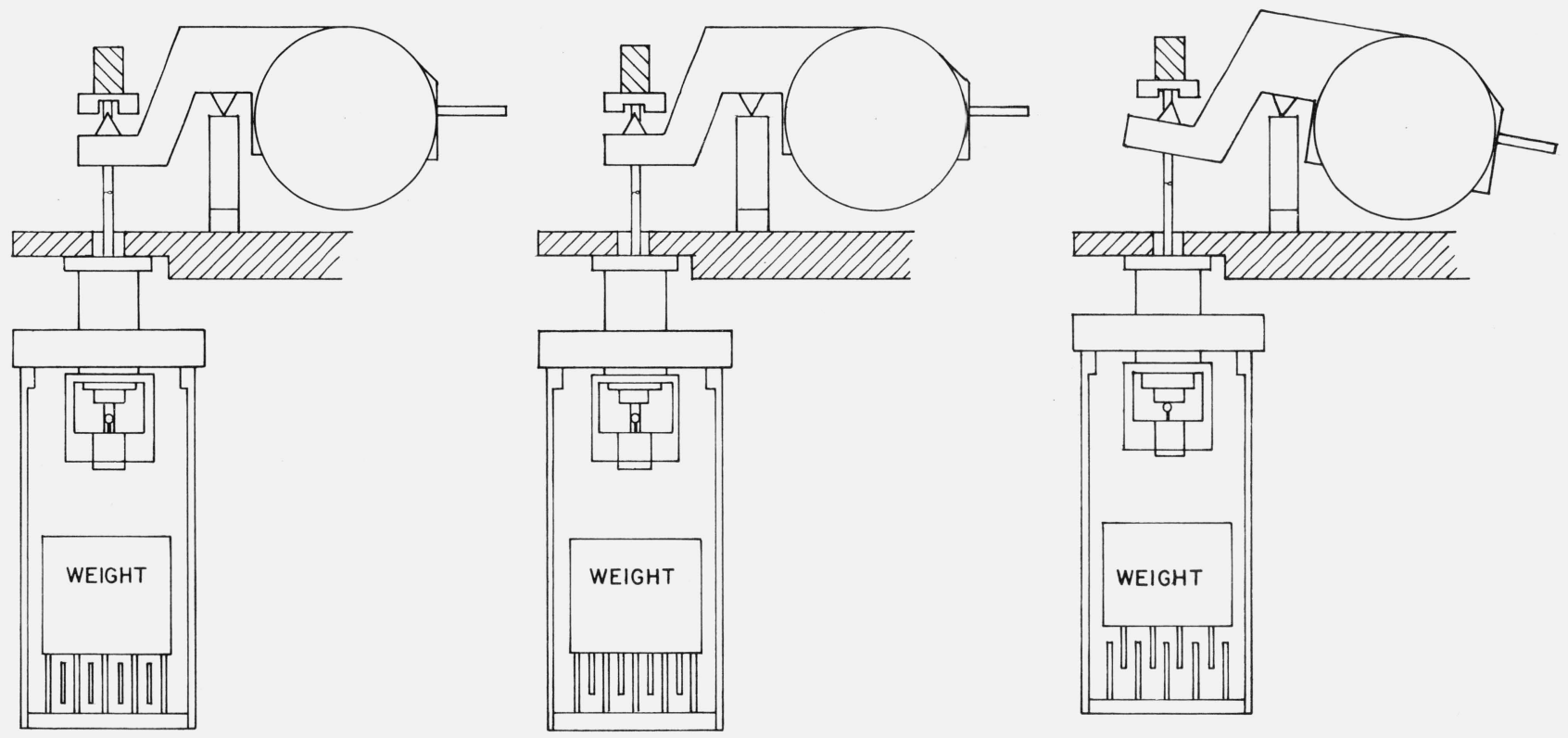

FIGURE 10. The constant load mode of arrestment.

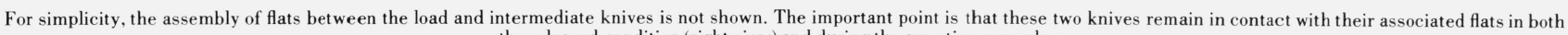
the released condition (right view) and during the arresting procedure. 


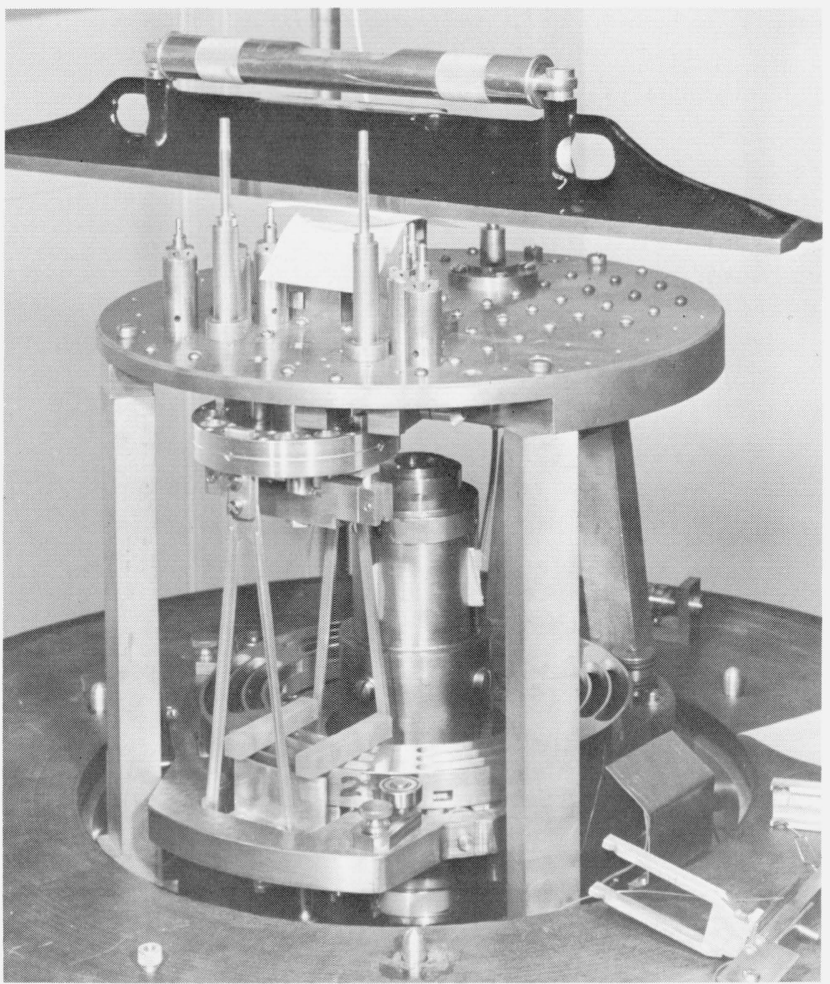

Figure 11. View of balance being leveled.

An optical device (fig. 12) was used to indicate when the adjustment was satisfactory. This device consisted of a light source (a galvanometer lamp) positioned above the balance and a small mirror placed on the part whose arrestment pins were being adjusted. The image of the filament of the galvanometer lamp was reflected onto the room ceiling, which served as a viewing screen. Lack of motion of image when the balance was released or arrested indicated proper adjustment.

The pan was leveled (fig. 11) by adding weights to either side, front, or back as required. The height of the weight carrier table was adjusted so that the weight carrier would clear the pan with the weight changing mechanism in the weight changing position, as the weight carrier is rotated during the weight changing operation.

Tests after the final beam adjustment indicated that the knife edges were parallel within about one part in $10^{7}$ and coplanar within about two parts in $10^{8}$.

\section{Operation}

The operation of the balance is straight forward, but in some aspects, indicated below, its operation differs from that of a conventional one pan balance. The balance is free swinging, therefore, the indication is obtained by taking turning points. The built-in sensitivity weight is controlled from outside the balance case. There are places for six weights on the balance's weight carrier any of which can be brought to the pan and placed on or removed from the pan by means of

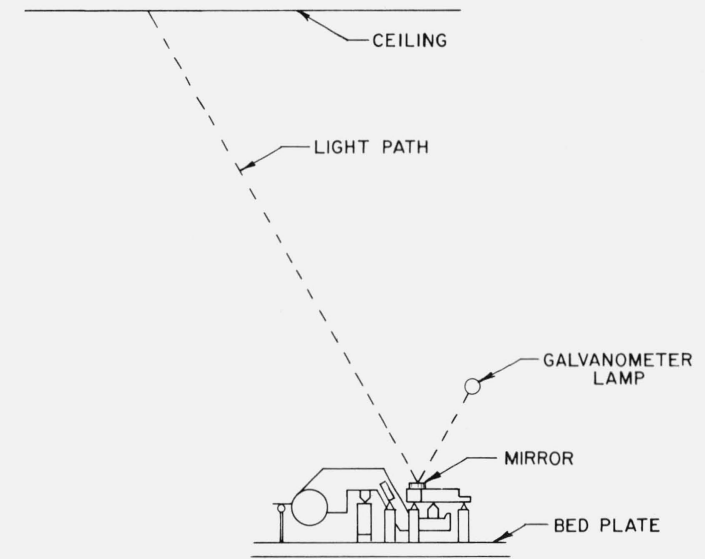

FIGURE 12. Schematic of optical system used in adjusting the arresting-alinement pins.

controls outside the balance. Thus after the weights have been placed in position, the weight on the pan may be changed and a whole series of measurements made without opening the balance case.

When the balance is opened for loading or any other reason, it should always be arrested in the full arrest mode and the weight carrier in the weight changing position. To open the balance the outer case is lifted off, set aside, and the lower part of the inner case raised (fig. 13). The weights are put in position on the weight carrier and successively brought into posi-

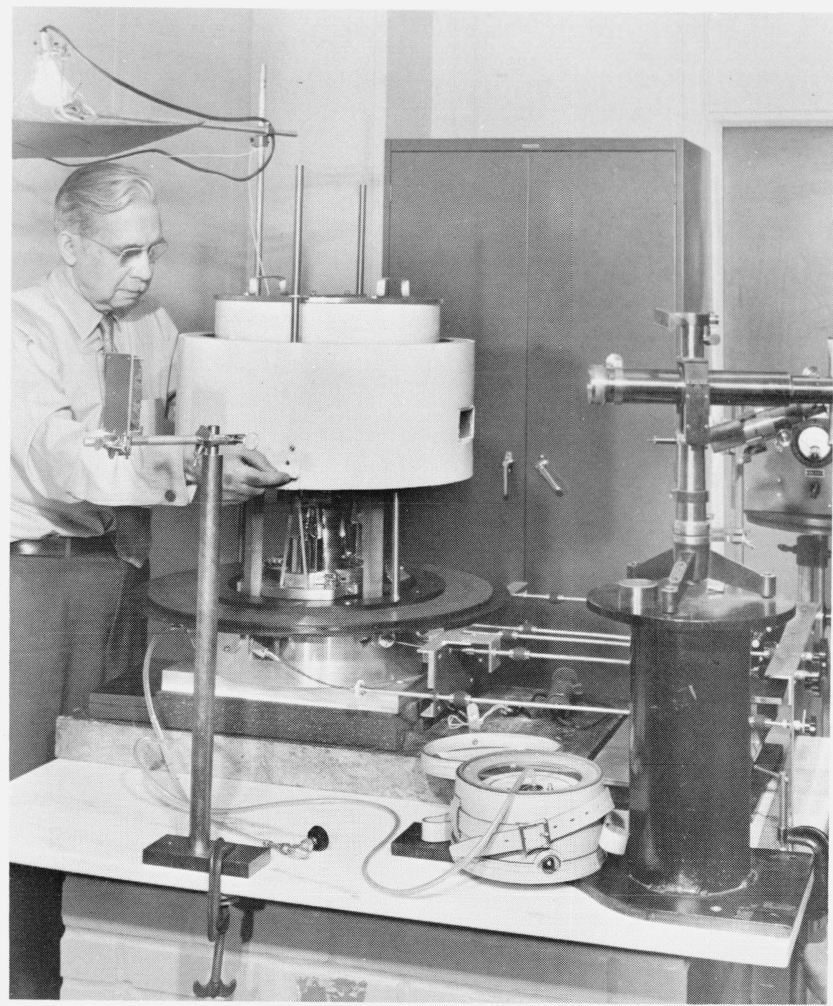

FigURE 13. View of the balance case being opened. 
tion over the pan for centering. As each weight is brought into position over the pan, it is mechanically centered by alternately placing it on and removing it from the pan, as the weight carrier and table are raised and lowered, until there is no movement of the pan when the weight is put on or removed from the pan.

As the balance is loaded, the position of each weight on the weight carrier is noted and the weights are trimmed to within a milligram of each other, by adding small known weights as required. The balance may now be closed, and the conditions within the balance case allowed to come into equilibrium before the weighings are commenced.

For optimum results, the balance should be exercised before the actual weighing operation is begun. With the selected weight in position over the pan, as indicated by the weight position indicator, and the beam brake applied, the full arrest control is turned to the released position. The weight carrier is then lowered to the weighing position, placing the weight on the pan. The brake is released, and as the balance approaches the equilibrium position the brake may be used to control the amplitude of the swing. After the indication has been noted, the balance is arrested in the constant load mode of arrestment, by raising the weight carrier to the weight changing position, thus removing the weight from the pan. The weight is placed on the pan as before, and the indication noted. The exercising is continued until the balance begins to repeat its indication, within its reproducibility.

When the balance has been exercised sufficiently, the actual measurements are begun. Since this is a one pan balance, all of the measurements are made by the substitution method weighing, preferably by the double substitution method according to an appropriate weighing design. The balance is always arrested in the constant load mode between the readings, even if it is only to apply or remove the sensitivity weight. The beam brake is always applied when arresting or releasing the balance to prevent large uncontrolled oscillation of the balance. The full arrest mode is used only at the beginning and end of a series of measurements, at the beginning to release the balance, at the end to arrest the balance. If the balance is to be left unused for any length of time, such as overnight, it is always left arrested in the full arrest mode of arrestment. If for some reason the balance has been arrested in the full arrest mode before the series of measurements has been completed, it is necessary to reexercise it before again making any measurements.

\section{Performance}

The balance's performance was evaluated through 13 series of measurements made over a period of a week. Three of these series involved four stainless steel $1 \mathrm{~kg}$ weights, designated SI, SII, SIII, and SIV. The SI, $1 \mathrm{~kg}$, served as the restraint. Another three of the series involved two platinum-iridium $1 \mathrm{~kg}$ weights, designated PI and PII, and two stainless steel $1 \mathrm{~kg}$ weights designated SI, and SV. The remaining seven series involved three platinum-iridium $1 \mathrm{~kg}$ weights, designated PI, PII, and PIII and one platinum weight, designated PIV.

All of the series of comparisons were made according to a weighing design, designated the 4-l's weighing design, in which four masses are compared in all possible combinations. In this design three degrees of freedom are available for estimating the error of the measurements. A pooled estimate of the standard deviation of one weighing was computed from the data developed during the thirteen series of comparisons. For this work, a double substitution weighing is defined as one weighing.

The barometric pressure, relative humidity, and temperature inside the balance were recorded at the beginning and end of each double substitution weighing. From this data, the average air density was computed for each weighing. Each measured mass difference was individually corrected for the buoyant effect of the atmosphere.

An analysis of the data indicates that in all instances the measurement process was operating in a state of statistical control.

The results of the thirteen series of measurements are shown in table 1 . The random portion of the uncertainty of each value, where all of the weights in a given series were of the same material, using $3 \sigma$ as the limit, is $7.8 \mu \mathrm{g}$.

It was noted that the sensitivity of the balance decreased during the course of a series of measurements. Since it took from about 25 to $30 \mathrm{~min}$ to complete one comparison between two weights by the double substitution method of weighing, from $2 \frac{1}{2}$ to 3 hours were required to complete a series of measurements according to the 4-1's weighing design - the design usually used. This means the knife edges were subject to the full load, continuously, for that period of time. The results shown in table 2 are typical.

After another series of similar measurements, which showed a similar decrease in sensitivity with time, the balance was arrested in the full arrest mode. That is, the knives were separated from their cooperating planes and completely relieved of any load. After about 4 hours, another sensitivity measurement was made. This measurement indicated that the balance had nearly recovered the sensitivity it had at the beginning of the series of measurements. Unfortunately, this data has been lost. The decrease in sensitivity was attributed to elastic deformation of the knife edges while they were loaded. The phenomenon was not investigated further.

The author wishes to express appreciation for the generous assistance and guidance received from many members of the NBS staff during the development of this balance. H. A. Bowman and P. E. Pontious contributed both practical and theoretical assistance and gave continuing support and encouragement throughout the development. The author is indebted to A. G. McNish and Karl G. Kessler for continued support and encouragement through the work, also to H. S. Peiser for encouragement throughout the development. 
TABLE 1. Summary of results of performance test

\begin{tabular}{|c|c|c|c|c|c|c|c|c|c|}
\hline \multicolumn{10}{|c|}{ True Mass Corrections } \\
\hline $\begin{array}{c}\text { Weight/ } \\
\text { series }\end{array}$ & $\begin{array}{l}\text { P II } \\
(\mathrm{mg})\end{array}$ & $\begin{array}{l}\text { P III } \\
(\mathrm{mg})\end{array}$ & $\begin{array}{l}\text { P IV } \\
(\mathrm{mg})\end{array}$ & $\underset{(\mathrm{mg})}{\mathrm{S}_{\mathrm{I}}}$ & $\begin{array}{c}\mathrm{S} \mathrm{v} \\
(\mathrm{mg})\end{array}$ & $\begin{array}{l}\text { S II } \\
(\mathrm{mg})\end{array}$ & $\begin{array}{l}\text { S III } \\
(\mathrm{mg})\end{array}$ & $\begin{array}{c}\text { S IV } \\
(\mathrm{mg})\end{array}$ & $\underset{\mu \mathrm{g}}{\mathrm{s}}$ \\
\hline $\begin{array}{r}1 \\
2 \\
3 \\
4 \\
5 \\
6 \\
7 \\
8 \\
9 \\
10 \\
11 \\
12 \\
13\end{array}$ & $\begin{array}{l}-0.0736 \\
-0.0722 \\
-0.0782 \\
-0.0708 \\
-0.0674 \\
-0.0718 \\
-0.0711 \\
-0.0797 \\
-0.0719 \\
-0.0780\end{array}$ & $\begin{array}{l}-0.7818 \\
-0.7836 \\
-0.7818 \\
-0.7806 \\
-0.7832 \\
-0.7806 \\
-0.7830\end{array}$ & $\begin{array}{l}-4.8394 \\
-4.8321 \\
-4.8390 \\
-4.8347 \\
-4.8396 \\
-4.8304 \\
-4.8313\end{array}$ & $\begin{array}{l}\text { latinum o } \\
\text { steel anc }\end{array}$ & $\begin{array}{l}\text { num-iridium } \\
\text { weights are }\end{array}$ & $\begin{array}{l}\text { Pooled esti } \\
\text { ation of } \\
\text { Pooled esti } \\
\text { ation of } \\
\text { all the w } \\
\text { were of } t\end{array}$ & $\begin{array}{l}\text { te of the } s \\
\text { hese mea } \\
\text { te of the s } \\
\text { measurem } \\
\text { hts in a gi } \\
\text { same mat }\end{array}$ & $\begin{array}{l}\text { dard devi- } \\
\text { ments. } \\
\text { dard devi- } \\
\text { s where } \\
\text { series } \\
\text { l. }\end{array}$ & $\begin{array}{l}4.8 \\
2.4 \\
3.0 \\
2.3 \\
3.4 \\
5.3 \\
2.1 \\
6.6 \\
4.0 \\
3.7 \\
7.8 \\
2.2 \\
3.4 \\
\\
4.3\end{array}$ \\
\hline
\end{tabular}

TABLE 2. Change in value of the division with time

\begin{tabular}{c|c}
\hline \hline $\begin{array}{c}\text { Inter- } \\
\text { comparison }\end{array}$ & $\begin{array}{c}\text { Value of the } \\
\text { Division }\end{array}$ \\
\hline$a_{1}$ & $0.1517 \mathrm{mg}$ \\
$a_{2}$ & $.1519 \mathrm{mg}$ \\
$a_{3}$ & $.1524 \mathrm{mg}$ \\
$a_{4}$ & $.1523 \mathrm{mg}$ \\
$a_{5}$ & $.1525 \mathrm{mg}$ \\
$a_{6}$ & $.1527 \mathrm{mg}$ \\
\hline
\end{tabular}

L. B. Macurdy contributed studies that aided in the development of the design. Randall M. Schoonover contributed design suggestions and assisted in testing the balance during the various stages of its development.

\section{Appendix}

The balance was loaned to the International Bureau of Weights and Measures for use in the International Bureau's Program of Mass Measurements, including the intercomparison of National Prototype Kilograms with the International Prototype Kilogram.

Prior to shipping the balance, representatives of the International Bureau of Weights and Measures spent from a week to a month at the National Bureau of Standards familiarizing themselves with the balanceits construction and operation. After they had become thoroughly familiar with the balance they oversaw the packing of the balance for shipment to the International Bureau at Sevres, France. The balance beam was hand carried, but the other parts of the balance were shipped by commercial air freight.

Because the International Bureau of Weights and Measures had not completed its new mass laboratory when the balance arrived the balance was temporarily installed in another laboratory. The International Bureau does not consider the weighing conditions in this laboratory to be good. After the balance had been set up in this temporary location, Georges Girard made several series of measurements, using four stainless steel kilograms, according to the 4-l's weighing design. The results of these measurements, in summary form, are shown in the graph below. There are 21
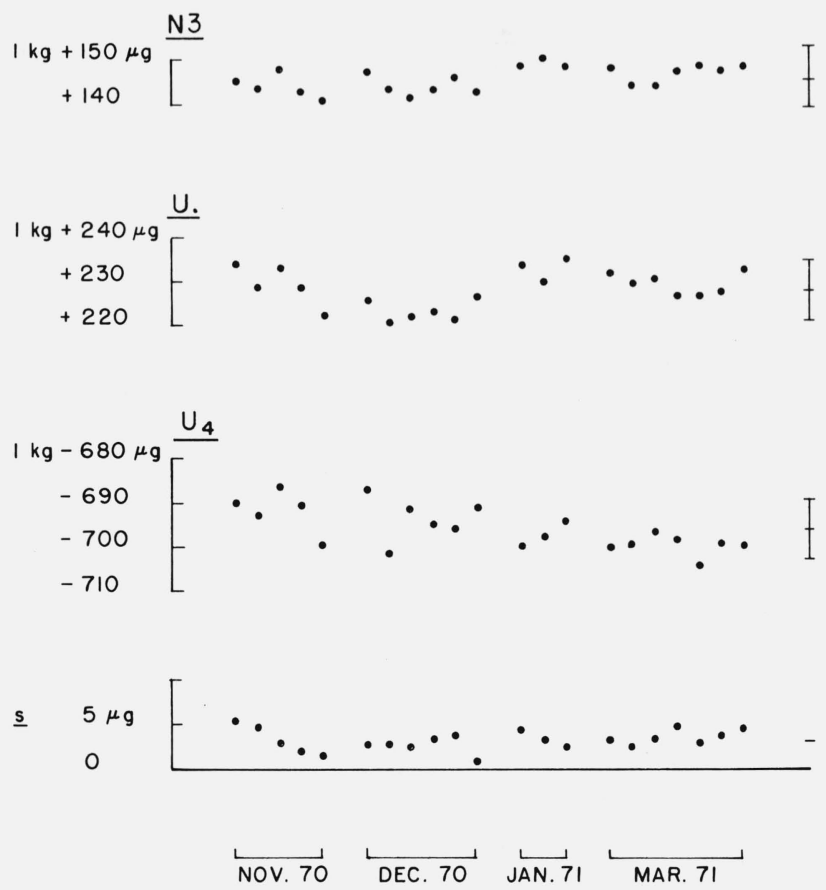
series of measurements and each series has three degrees of freedom available for estimating the error of measurement. The mean standard deviation on the basis of 63 degrees of freedom is $3.2 \mu \mathrm{g}$, and the measurement uncertainty of any individual value found is $6.8 \mu \mathrm{g}$.

\section{References}

[1] Peiser, H. S., State Mass Standards, Report of the 45th National Conference of Weights and Measures, June 8, 1960; p. 45.

[2] Almer, H. E., Bowman, H. A., Jensen, M. W., Macurdy, L. B., Peiser, H. S., and Wasko, B., A Direct-Reading Two-Knife 50-Pound Balance of High Precision Suitable for State W eights and Measures Laboratories., J. Res. Nat. Bur. Stand (U.S.), 68C (Eng. and Instr.) No. 3, 14l-154 (July-Sept. 1964).

[3] Bowman, H. A., and Almer, H. E., Minimization of the Arrestment Error in One-pan, Two-knife Balance Systems, J. Res. Nat. Bur. Stand (U.S.)., 67C (Eng. and Instr.), No. 3, 227-235 (JulySept. 1963).

[4] Bowman, H. A., and Schoonover, R. M., Procedure for High Precision Density Determinations by Hydrostatic Weighing, J. Res. Nat. Bur. Stand (U.S.), 71C (Eng. and Instr.), No. 3 179-198 (July-Sept. 1967).

[5] Macurdy, L. B., Response of Highly Precise Balances to Thermal Gradients, J. Res. Nat. Bur. Stand (U.S.), 68C (Eng. and Instr.) 135-140 (July-Sept. 1964).

(Paper 76C1\&2-326) 